\title{
Visualization of Gas Tungsten Arc Welding Skill Using Brightness Map of Backside Weld Pool
}

\author{
Takanori Hino $^{1 *}$, Syota Fujioka ${ }^{1}$, Shin Kira ${ }^{1}$, Shigeru Kato ${ }^{1}$, Takuro Sakiyama ${ }^{1}$, Ryo Kato ${ }^{1}$, \\ Toshio Matsubara ${ }^{2}$ and Hiroyuki Yanagimoto ${ }^{3}$ \\ 1 National Institute of Technology (KOSEN), Niihama College, 7-1 Yagumo-cho, Niihama, Ehime 792-8580 Japan \\ 2 Tokushima Prefectural Industrial Technology Center, 11-2 Saika-cho, Tokushima, Japan \\ 3 Shikoku Kakoki Co.,Ltd, 10-1 Kitajima-cho, Tokushima, Japan \\ * Corresponding author: Fax: 81-897-37-7802, and/or e-mail: hino@mat.niihama-nct.ac.jp
}

\begin{abstract}
Many companies have been attempting to transfer the skills and knowledge of skilled workers to other inexperienced workers. The establishment of an efficient training method is also desired for gas tungsten arc welding (GTAW), which has high demand in the production fields of industrial equipment. This study focused on the brightness of the backside weld pool changing under GTAW conditions. The backside weld pool images during welding of a stainless steel plate were taken with a charge coupled device (CCD) camera from the bottom of the welding stage made of glass. The situation of the weld pool at the backside of the plate was visualized by a brightness map of the backside weld pool with the brightness on the horizontal axis and the number of pixels on the vertical axis. From this map, the torch control technique and quality of the backside bead could be numerically evaluated. Therefore, the map suggests that the GTAW skills could be visualized. This could improve welding skill easily and also contribute to highly efficient training, education, and transfer of skills, because the brightness map of the backside weld pool reveals the weaknesses of the welder.

Key words: GTAW, stainless steel, brightness, backside weld pool, visualization, skill training
\end{abstract}

\section{INTRODUCTION}

Sustainable long-term employment of young engineers as well as the development of welding engineers, who are to become next generation skilled workers, is a major issue. Companies and industry organizations have pressing needs to find solutions to these issues [1]. Among welding methods, gas tungsten arc welding (GTAW), which is capable of providing high quality welded joints, can be applied for a wide range of metals, and it is indispensable to the manufacturing industry. In the manufacturing of food production equipment, welding work accounts for $80 \%$ of equipment assembling. Many issues arise as a result of poor welding. In addition to maintaining and improving the skills of engineers, manufacturing sites face the challenge of securing young people for transferring the skills that will forge the future, as well as progressing with reforms for training and education measures [2].

However, skilled engineers are different from young low ranked applicants and employees, in that there are many who are, as tradesmen, highly advanced in craftsmanship, although poor at teaching [3]. Transferring skills to the next generation has become a serious issue, because it has been influenced by the decline of the workforce, as well as the aging population and declining birthrate. Additionally, there are concerns over the deteriorating skills of instructors due to the rapid alternation of generations. Welding, in particular, is a form of craftsmanship that often relies on knack and intuition, which even until today, have been cultivated by skilled workers. Skills training requires time and lots of money.
Great importance has been placed on proposing an approach that stimulates a novice welder's willingness to learn the knack and expertise for the future [4]. In recent years, there have been reports of welding training that employs virtual welding simulators utilizing welding skill digitizers $[5,6]$ that display multiple parameters on radar charts using various sensors and high precision cameras, as well as virtual reality goggles [7] that do not generate an actual arc. The authors believe that, for training inexperienced workers, it is more effective to resolve one item of improvement at a time while performing actual welding. We focused on the brightness of the backside weld pool [8-10] changing by welding conditions.

Therefore, in this study, welding was visualized to enable inexperienced GTAW novices to continue training while confirming the state of penetration, as well as assessing the areas of improvement. Then, the efficiency of the training was verified.

\section{EXPERIMENTAL METHOD}

2.1 Bead on Plate Welding

The test material used was SUS304-2B with a length, width, and thickness of $100 \mathrm{~mm}, 50 \mathrm{~mm}$, and $3 \mathrm{~mm}$, respectively, with a groove $1.0 \mathrm{~mm}$ wide and $0.5 \mathrm{~mm}$ deep using a shaper to simulate the butted portion in the center. For GTAW, welding skill training equipment (Shikoku Kakoki Co., Ltd) composed of a DC Pulse TIG welder (DT300PII by DAIHEN Co., Ltd), a welding stage, a stepper motor for moving a torch, a charge coupled device (CCD) camera (XC-EI30 by Sony), a monitor, and a 
computer was used $[11,12]$. The welding bead was formed at a uniform velocity using a stepper motor and manually welded by both students of novice GTAW and welding technicians from a local company. The welding technicians from a local company were holders of WES 8221 Stainless Steel Welder qualification, certified by The Japan Welding Engineering Society. A bead on plate weld was performed with the following GTAW conditions:

- Tungsten electrodes containing $2 \%$ ceria $(2.4 \mathrm{~mm}$ in diameter, a tip angle of $60^{\circ}$, and a protrusion length of 3 $\mathrm{mm})$

- A $15^{\circ}$ torch push angle from the vertical plane

- Arc spacing distance of $1.5 \mathrm{~mm}$ between the electrode and test plate

- Argon shielding gas flow rate of $7 \mathrm{~L} / \mathrm{min}$ for torch and backside

- Welding current of 80-120 A

- Welding speed of 60-100 $\mathrm{mm} / \mathrm{min}$

- Weld length of $70 \mathrm{~mm}$

The novices performed manual welding twice. For the first weld attempt, the novices were asked to watch a video of a weld pool by an experienced worker and observe their actual welding process. Then, they were explained the basics, practiced the fundamental torch movements on a dispensable plate, and then began welding. For the second weld attempt, they compared the appearances of their beads as well as the weld pools during welding recorded in the video, which they did in the first weld attempt, to the results of an advanced welder. After areas of improvement suggested by the novices themselves were reviewed by instructors, the novices performed the weld.

In the criteria for the JIS Z 3821 Welder qualification, bead undulation and bead width are assessed separately. In this study, beads of uneven widths are defined as a guide to assess both comprehensively. The uneven bead (Wu) is substituted with the trainees' surface bead width (Wi) and the average bead width (Wa) into Equation (1) at an interval of $5 \mathrm{~mm}$ of the portion with $10 \mathrm{~mm}$ removed from both ends and expressed as a standard deviation.

$W_{u}=\sqrt{\frac{\sum_{i=1}^{n}\left(W_{i}-W_{a}\right)^{2}}{n-1}}$

That is, a bead is linear and has a uniform width if $\mathrm{Wu}=$ 0.0 .

\subsection{Brightness of Backside Weld Pool}

During welding, both the surface and the backside of the plate were filmed simultaneously from the top of the welding stage and under the glass stage. A CCD camera

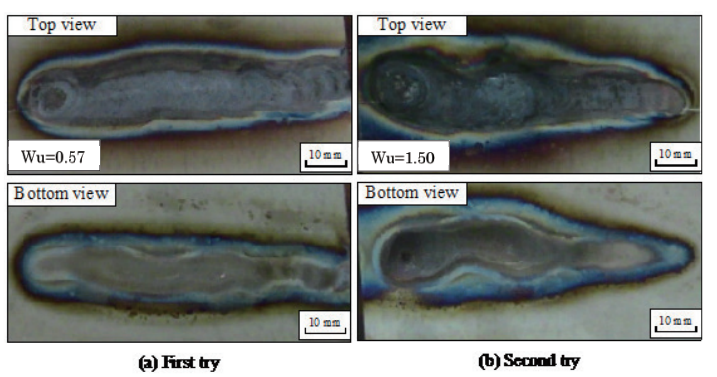

Fig. 1 Appearances of weld bead for inexperienced welder. with a near infrared ray band pass filter $(940 \mathrm{~nm} \pm 2 \mathrm{~nm})$ and UV blocking filter $(<390 \mathrm{~nm})$ was used for filming. Stainless steel plate was set on a back-shield box purged with Ar gas to prevent oxidation on its backside. The bottom of this back-shield box was made of glass. The back side of the stainless steel plate is not in close contact with the glass plate. Therefore, existence of the glass plate does not influenced on welding situations.

Apart from the welders, others were also able to see the state of the weld pool on the video as they were recorded and displayed on a monitor along with the weld current and the voltage. Images of the backside weld pool (318 pixels $\times$ 182 pixels) captured every $10 \mathrm{~mm}$ from the toe were used to analyze the brightness value. The images of the backside weld pool were composed of 256 levels of grayscale, and the number of pixels of each gradient was obtained from them. The brightness value B was obtained by using the gradation value $\mathrm{N}$, the number of pixels $\mathrm{P}$, and image size $\mathrm{S}$ to calculate the average value of the histogram of gradation values according to Equation (2) [13].

$B=\frac{\sum(N \times P)}{S}$

The state of an analyzed backside weld pool was evaluated by creating a brightness map for the backside weld pool with brightness value $B$ set to the horizontal axis and the number of pixels $\mathrm{P}$ set to the vertical axis. Furthermore, cases with uniform velocity torch movement using a stepper motor were similarly analyzed to compare cases with manual torch movement.

\section{EXPERIMENTAL RESULTS AND DISCUSSION}

3.1 Surface Bead

The top priority was to acquire torch movement that produces a straight-lined bead with no undulation of uniform width. By generating an arc on a dispensable plate and practicing tracing grooves made with a shaper, the $\mathrm{Wu}$ value in the second weld attempt approached 0.0 , which is a theoretically uniform bead width. Although there were individual differences, improvements in the ability to control torch movement were confirmed by comparing the surface bead unevenness (Wu) while observing each other's bead appearances.

However, there were novices whose $\mathrm{Wu}$ values were lower in the second weld attempt than the first, as shown in Fig. 1. Although the surface beads in the first weld attempt were straight and equal in width, burnt areas that remained on the backside indicate that sufficient penetration was not achieved. Therefore, advice was given for penetration to be achieved. It is likely that following this advice too strictly caused overheating and wide bead width, resulting in poor torch movement control in the second weld attempt. If GTAW is used for piping and the first layer of steel in the actual welding, it is necessary to obtain a back bead weld. Therefore, skills training was conducted while the
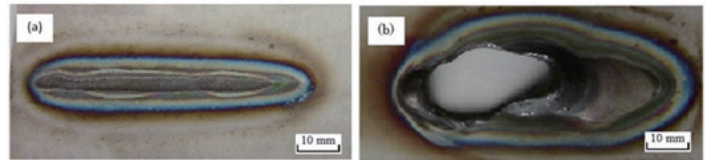

Fig. 2 Appearance of backside bead under (a) low heat input and (b) high heat input. 
relationship between the brightness map for the backside weld pool, which visualizes the state of penetration, and one's torch movement ability was reviewed.

\subsection{Brightness Map of Backside Weld Pool}

Fig. 2 shows the appearance of a backside bead when welded at a uniform velocity with (a) low heat input and (b) high heat input. When welded at a uniform velocity under the conditions of an $80 \mathrm{~A}$ welding current and a speed of 80 $\mathrm{mm} / \mathrm{min}$ when an arc is struck, the brightness value was 10 and pixel number was 9,625 at the position where the back bead weld was obtained. In contrast, when welded under the conditions of a 120 A current and a speed of $30 \mathrm{~mm} / \mathrm{min}$, the brightness value was 106 and pixel number was 45,376 at a position $30 \mathrm{~mm}$ of the welding length directly before burn through occurred. Under these conditions, the pixel number was 21,334 at $10 \mathrm{~mm}$ from the toe of the weld. Because brightness is saturated above the melting point, in this study, the back bead weld forming range, which forms a weld pool with an obtained back bead weld, was set to have a brightness value of 10 or more and the number of pixels with an average brightness value of 10 or more was between 10,000 and 20,000, inclusive.

Fig. 3 shows the state of penetration by skilled workers on a brightness map of a backside weld. The skilled workers had seven years of on-site construction work experience as advanced welders and one year as intermediate level welders. The hatched area shows the back bead weld forming range mentioned previously. The brightness map of the advanced welders' backside weld pool showed a brightness value of 15 , and the number of pixels for a gradation value of 10 or more converged to 15,000 . The unevenness of the surface bead (Wu) acquired from Equation (2) was also 0.36, and the width of both the surface and the backside had appearances of a uniform bead. For the intermediate level workers, the brightness values and number of pixels were larger than those of the advanced welders and had a broader range of dispersion. As for the appearance of the backside bead, there was little irregularity across the entire area, and a uniform width with sufficient penetration was obtained. These were used as model data, along with the video data, for training novices.

Fig. 4 shows the brightness maps of novice A's backside weld pools and the appearances of the backside bead for the first and second weld attempts. In the image are the results obtained from a uniform velocity weld at $60 \mathrm{~mm} / \mathrm{min}$ with a stepper motor using a torch positioned at a $1.5 \mathrm{~mm}$ spacing and a $15^{\circ}$ push angle with an $80 \mathrm{~A}$ weld current that began at the same time the arc was generated. Under movement at a uniform velocity, the brightness and number of pixels increased as the length of the weld increased, resulting in a brightness value of 21 at $40 \mathrm{~mm}$ and over. This is because of the increase in heat accumulated by the plate in addition to the welding heat as the length of the weld increases.

To obtain a uniform bead, control of movement speed is necessary. In novice A's first weld attempt, the brightness value and number of pixels increased in the same manner as the uniform velocity welding, and it could be seen from the appearance of the backside bead that sufficient penetration was not obtained until reaching a weld length of $30 \mathrm{~mm}$. The backside melting range and penetration were also observed in the region $40 \mathrm{~mm}$ onwards from the toe. These results show that the torch was moved at the same time an arc was struck, and the torch's movement was similar to that of uniform velocity welding across the entire area.

Before the second weld attempt, advice was given to perform a weld that was assumed to be at the $40 \mathrm{~mm}$ spot on the surface weld pool while comparing the surface and backside weld pools in the video during welding and the exterior appearance, as well as the brightness map of the backside weld pool, to those of the advanced welders. In the second weld attempt, the weld was within the backside melting range and converged to a brightness value of 14 and approximately 13,000 pixels. Through observation of the appearance of the backside bead, penetration was confirmed to have been achieved across almost all areas.

Although many of the novices were able to form a straight bead tracing the groove imitation gap on the first weld attempt, they were unable to achieve a width with uniform penetration in the backside bead. In the second weld, approximately $30 \%$ of novices achieved backside melting range and improved their torch movement abilities, which allowed penetration by referring to the brightness maps of the backside weld pool, personally suggesting

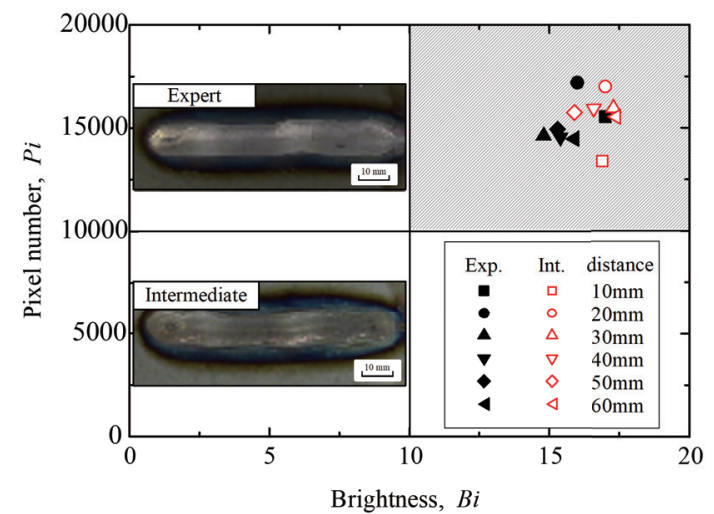

Fig. 3 Brightness map of backside molten pool for expert and intermediate welder.
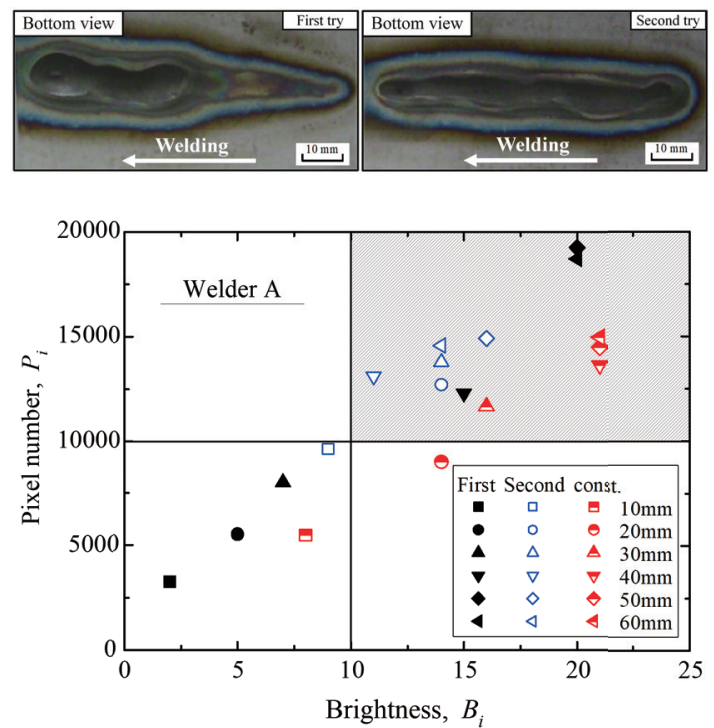

Fig. 4 Appearances of bottom bead and brightness map of backside molten pool for welder A. 

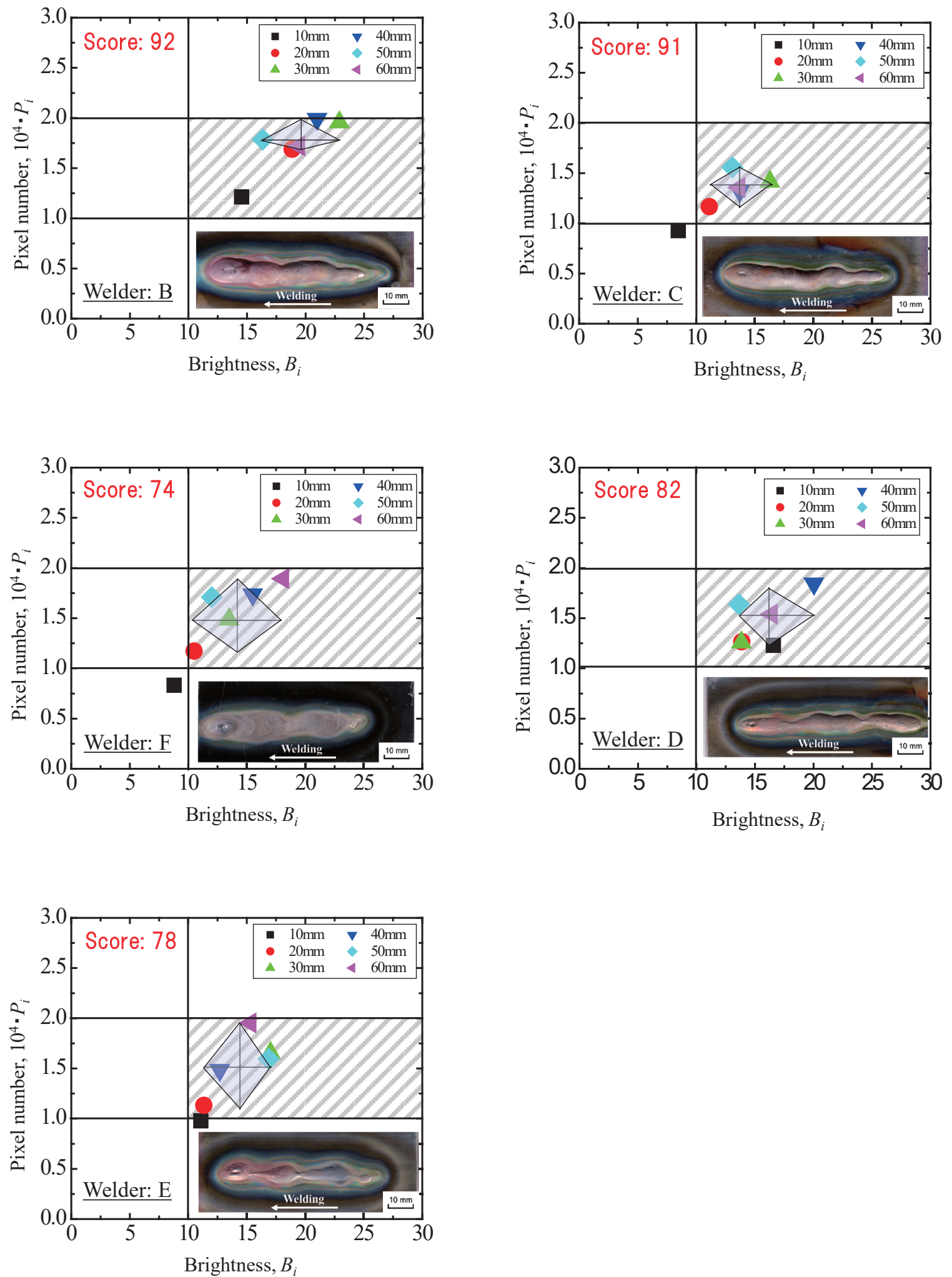

Fig. 6 Appearances of bottom bead and brightness map of backside molten pool for novice welders. 
areas of improvement, and understanding aspects that require correcting. Therefore, the map enables the welding state to be visualized, allows novices to assess penetration, and helps them easily understand instructions provided by skilled workers. To stimulate further the willingness to develop these skills, the scores for torch movement skills were calculated, and the differences in skills among workers were clarified.

\subsection{Quantification of Welding Skill \\ Torch Movement:}

When torch movement is controlled to obtain a stable penetration in the brightness map of a backside weld pool, each position on the B-P plot points would converge similarly to those of a skilled worker. Therefore, it was decided to compare the ranges of dispersion as the torch movement skill of each welder. Brightness value B' was normalized via Equation (3) with a range of 0-100 using the brightness value at each welding position $(\mathrm{Bi})$, the maximum brightness during welding (Bmax), and the minimum brightness value (Bmin). Similarly, the number of pixels (P') was also normalized via Equation (4).

$$
\begin{aligned}
& B^{\prime}=\frac{B_{i}-B_{\min }}{B_{\max }-B_{\min }} \times 100 \\
& P^{\prime}=\frac{P_{i}-P_{\min }}{P_{\max }-P_{\min }} \times 100
\end{aligned}
$$

The dispersion range of the brightness map approximated the average values of the normalized brightness value (B') and the number of pixels (P') into a rhombus shape. The area of the range of dispersion $(\mathrm{Si})$ is calculated via Equation (5) using the post normalized maximum brightness value (B'max) and post normalized minimum brightness value (B'min), as well as the post normalized maximum pixel number (P'max) and post normalized minimum pixel number (P'min).

$S_{i}=\left(B_{\text {max }}^{\prime}-B_{\text {min }}^{\prime}\right) \times\left(P_{\text {max }}^{\prime}-P_{\text {min }}^{\prime}\right)$

Each novice's torch movement skill was relatively evaluated out of 100 points to the advanced welders' area

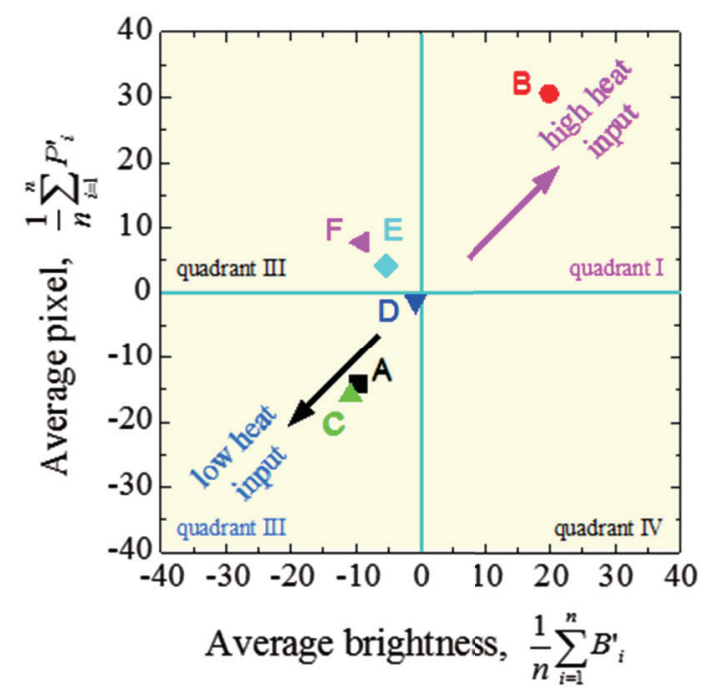

Fig. 7 Convergence position of the brightness map. of dispersion range. That is, the skill points (Ti) were determined by taking the maximum area of the dispersion range produced by novices applicable in this study (Smax), the area of the advanced welders' dispersion range (Smin), and the area of the dispersion range of the target novice's score $(\mathrm{Si})$, and substituting the square root of each into Equation (6) to make the units one dimensional.

$T_{i}=\frac{\sqrt{S_{\max }}-\sqrt{S_{i}}}{\sqrt{S_{\max }}-\sqrt{S_{\min }}} \times 100$

Fig. 5 shows the brightness map of the backside weld pool, which includes the calculated torch movement skill score (Ti). The approximated range of dispersion and the bead's appearance are shown in the figure. Scores for torch movement skills increased in the backside weld pool brightness maps, which had little dispersion. The backside bead was also confirmed to be uniform. As a result, it was possible to compare by quantifying torch movement skill in addition to visualizing weld states. However, although high-scoring welders $\mathrm{B}$ and $\mathrm{C}$ obtained almost the same score, each had varying convergence positions. The convergence position is believed to relate the average width of the backside bead. Therefore, the quality of the backside bead was evaluated from the convergence position.

\section{Backside Bead Quality:}

Fig. 6 shows the average backside bead quality of each welder with the advanced welders' convergence position as the origin. It was observed that $\mathrm{B}$, who obtained a torch movement skill score of more than 90 points, was positioned in the first quadrant, and had a high average brightness and high average number of pixels, as well as excess heat input. Contrastingly, for $\mathrm{C}$, it was observed that the point of convergence was positioned in the third quadrant, had a low average brightness and low average number of pixels, and had insufficient heat input because the torch movement was too fast. The second quadrant is where the average brightness is low, while the number of pixels is large. A lack of concentration for the arc is considered to have caused the wide area to become heated. That is, the torch's push angle was considered too large.

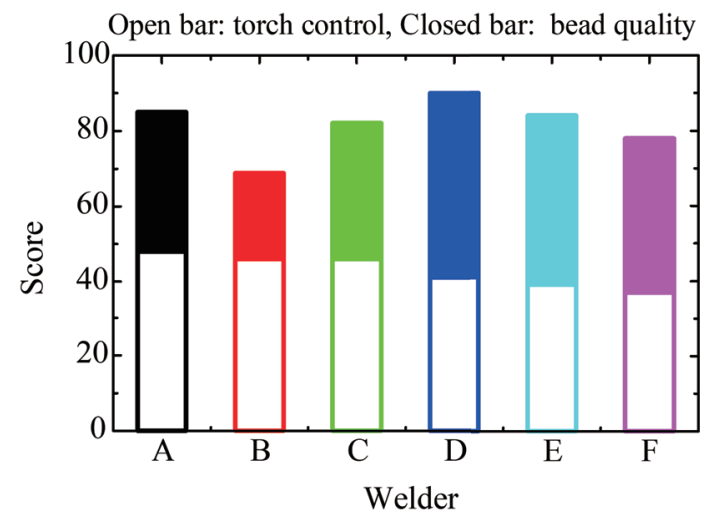

Fig. 8 Numerical evaluation of the GTAW skill. 
Areas of improvement could be suggested including the manner of comparing the quality of beads, as just described. Similarly, it is considered that a higher energy density heat source was used in the fourth quadrant where the brightness was high and the number of pixels was low. In this study, no converging weld was confirmed in the fourth quadrant.

Numerical evaluation was performed on the quality of an average backside bead. The distance between the advanced welder's convergence value and the convergence position of each welder in Fig. 6 was determined via Equation (7).

$D i=\sqrt{\left(B^{\prime} \min ^{-B^{\prime}}{ }_{i}\right)^{2}-\left(P_{\text {min }}^{\prime}-P^{\prime}{ }_{i}\right)^{2}}$

This distance (Di) was substituted into Equation (8), and the difference from the advanced welder was taken to obtain the score of a novice's average backside bead quality (Qi).

$\mathrm{Q}_{i}=\frac{\sqrt{D_{\max }}-\sqrt{D_{i}}}{\sqrt{D_{\max }}-\sqrt{D_{\min }}} \times 100$

The training results are shown in Fig. 7, which include a comprehensive evaluation of the GTAW torch movement skill points and the score for the average backside bead quality. The novices were taught the torch movement skills for obtaining a smaller dispersion within the backside weld pool range, beginning with practicing obtaining a straight surface bead. Next, they were able to acquire the skills to perform penetrating welds by practicing converging to brightness values of 15 pixels and 15,000 pixels, similar to advanced welders. By applying the brightness map of the backside weld pool capable of visualizing the weld state to solve each problem, they were able to make progress in training while reviewing their own level and areas of improvement.

\section{SUMMARY}

In this study, weld states were visualized, and skills were numerically assessed to develop the skills needed to form back bead welds for inexperienced novices in GTAW. Below is a summary of the results obtained.

(1) The brightness map of the backside weld pool is able to visualize the weld state and can be used to train how to form back bead welds.

(2) It was possible to visualize and numerically evaluate torch movement skills to obtain a back bead weld with sufficient penetration.

(3) It was possible to visualize and numerically evaluate the quality of the backside bead.

(4) It was possible to simplify and indicate the areas of improvement with results to be expected in the novices' voluntary training.

(5) It was possible to train while clearing the following issues one at time in the order of: practicing torch movement in the weld pool range while referring to the brightness map of the backside weld pool, improving one's score in torch movement skill, and improving one's bead quality evaluation score.

Based on these results, the training, which used brightness maps of backside weld pools as a reference, clarifies the issues among GTA welders, is a method to improve efficiently the novices' welding abilities, and can be expected to contribute to the passing down of welding skills to the next generation.

\section{ACKNOWLEDGMENTS}

We would like to express our gratitude to the "Next Generation's Researcher Support Program" by The Japan Welding Engineering Society for its support. We are also grateful to Miyoshi iron works Co., Ltd. for their important contributions to the experiments.

\section{REFERENCES}

[1] K. Nishiguchi, Quarterly journal of the Japan Welding Society, 69, 6-15 (2000)

[2] M. Yuda and M. Tao, Kawada technical report, 28, 106-107 (2009)

[3] H. Momura, Quarterly journal of the Japan Welding Society, 17, 150-154 (1999)

[4] Y. Okumoto, Quarterly journal of the Japan Welding Society, 25, 309-315 (2007)

[5] M. Sakuma and S. Asai, Journal of the Japan Welding Society, 75, 653-657 (2006)

[6] S. Asai, T. Ogawa and H. Takebayashi, Welding in the world, 56, 26-34 (2012)

[7] A. P. Byrd, R. T. Stone, R. G. Anderson, and K. Woltjer, Welding Journal, 94, 389-395 (2015)

[8] M. Tanaka, Welding International, 19, 870-876 (2005)

[9] A. S. Baskoro, M. Kabutomori, Y. Suga, Journal of Solid Mechanics and Materials Engineering, 2, 582-592 (2008)

[10] Y. Ogawa, Journal of High Temperature Society, 37, 99-107 (2011)

[11] T. Hino, Welding Technology, 1, 83-86 (2016)

[12] T. Hino, Welding Technology, 9, 98-99 (2016)

[13] M. Nagata, The journal of the Institute of Image Information and Television Engineers, 61, 1602-1605 (2007)

(Received May 10, 2019; Accepted July 10, 2019; Published Online October 1, 2019) 